\title{
Cutting Across Discipline Boundaries: Statistical Prospects in Disclosing and Handling the Workings of Natural Biodiversity
}

\author{
Crispin M. Mutshinda (Corresponding author) \\ University of Helsinki \\ Department of Mathematics and Statistics \\ P.O. Box 68 (Gustaf Hällströmin katu 2b) \\ FIN-00014 Helsinki, Finland
}

Tel: 358-919-151-439 E-mail: crispin.mutshindamwanza@helsinki.fi

The author acknowledges financial support from the Academy of Finland (project no. 205371).

\begin{abstract}
Ecologists have long sought to comprehend the mechanisms that generate, maintain and shape natural biodiversity. Such an attempt is inherently an interdisciplinary research project which involves a holistic understanding of biological systems, sound modeling, computational and analytical techniques, and high quality data collection. Along this interdisciplinary line, some degree of sophistication in statistical practice is necessary. This note points out a number of promising avenues in this respect.
\end{abstract}

Keywords: Assembly rule, Environmental covariance matrix, Hierarchical Bayesian framework, Neutrality, Niche, Variable selection

\section{On current assembly theories and surrounding controversies}

Understanding the mechanisms that generate, maintain, and structure natural biodiversity is an important research focus in ecology. An as yet unresolved debate concerns whether ecological communities are mere collections of species undergoing random drift in localities to which they happen to disperse, or whether they are structured assemblages emerging from interactions between species as they coexist. The latter view underlies "conventional" ecological wisdom which emphasizes niche partitioning as key to stable coexistence of ecologically similar species (e.g., Gause 1934, Hutchison 1957, Armstrong \& McGehee 1980). However, the niche assembly perspective has been recently called into question for its alleged inability to explain many observed patterns in nature (e.g., Hubbell 2001, Zhou \& Zhang 2006), and its failure to explicitly account for dispersal limitation and speciation (Hubbell 2001). On the other hand, the yet single trophic-limited neutral assembly theory of community structure and biodiversity (e.g., Bell 2000, Hubbell 2001) which considers stochastic demographic and dispersal processes as the leading forces behind biodiversity patterns has been extensively falsified (e.g., Engen et al. 2002; McGill 2003, Etienne \& Olff 2004, Maurer \& McGill 2004, Poulin 2004, Chase 2005, Turnbull et al. 2005, Williamson \& Gaston 2005, Adler et al. 2007, Mutshinda et al. 2008). Most empirical assessments of the neutral theory have revealed that trophically defined communities often fluctuate more than the neutral theory would suggest (e.g., Dornelas et al. 2006, Mutshinda et al. 2008). This excess of variability over expectations of the neutral model results presumably from species differential responses to environmental variability and potential unbalance in competitive abilities across species.

Ecologists increasingly admit that biotic interactions and abiotic random forcing typically act in concert with demographic stochasticity (drift) to shape natural communities. Put another way, coexistence mechanisms involve both neutral and non-neutral forces (e.g., Gravel et al. 2006, Adler et al. 2007). The interest for analysts is therefore to evaluate the relative importance of a range of prospective factors beyond the limits of the traditional dichotomous hypotheses of the form neutrality versus the niches (e.g., Turnbull et al. 2005) or compensatory dynamics versus environmental forcing (e.g., Houlahan et al. 2007). As eloquently put by Bjørnstad \& Grenfell (2001), "the interplay between noise and determinism in ecological systems presents conceptual and methodological challenges distinctive from those in other dynamical systems". Teasing out fluctuations in species abundances and diversity measures into 
contributions from demographic stochasticity, environmental forcing, and intra-/inter-specific interactions, turns out to be an interdisciplinary research project. It involves a holistic understanding of biological systems, elaborate modeling, computational, and analytical techniques, and high quality data collection. Some degree of sophistication in statistical practice is necessary, and a number of promising prospects in this respect can be identified.

\section{Statistical prospects in disclosing and handling biodiversity processes}

In this section we identify a number of statistical prospects in connection with an interdisciplinary approach to disclosing and handling the workings of natural biodiversity.

First, the increasingly popular hierarchical Bayesian (HB) framework (e.g., Gelman et al. 2003, McCarthy 2007) for statistical modeling and inference provides much flexibility for elucidating complex ecological relationships (e.g., Diez \& Pullian 2007). Modern variable selection techniques in the vein of stochastic search variable selection (George \& McCulloch 1993) have the potential to identify the relevant biotic interactions through Bayes factors of the odds probabilities of including versus not including a particular interaction into the model. It is worth emphasizing that the number of interaction coefficients increases drastically with the number of species involved. This may also induce identifiability problems since the number of fitted parameters may exceed the number of single data points. One way around the expanding model dimensionality is to take advantage of the $\mathrm{HB}$ approach to assign to the interaction coefficients identically distributed priors so that only hyperparameters (i.e., parameters of priors) appear as free parameters.Third, the variance decomposition required for identifying the forces that drive fluctuations in population abundances, when carried out within a Bayesian framework, permits full consideration of uncertainty about the fitted parameters. Fourth, assembly rules such as neutrality and niche segregation can be examined through the fitted parameters such as interaction coefficients and species-specific and shared responses to environmental perturbations. It goes without saying that the model fitting will typically require a resort to numerical methods such as Markov chain Monte Carlo (MCMC) (e.g., Gilks et al. 1999). MCMC can easily be implemented through existing software such as Win-/Open-BUGS (Spiegelhalther et al. 2003, Thomas et al. 2006).

\section{Conclusion}

Teasing out the inherently complex workings of natural biodiversity requires broadly applicable frameworks cutting across discipline boundaries to combine a thourough understanding of biological systems with sound modeling, computational, and analytical methods and, just as important, the collection of high quality data. Along this interdisciplinary line, this note has identified a number of promising statistical prospects.

\section{References}

Adler, P. B., HilleRisLambers, J. \& Levine, J. M. (2007). A niche for neutrality. Ecology Letters 10, 95-104.

Alonso, D., Etienne, R.S. \& McKane, A.J. (2006). The merits of the neutral theory. Trends in Ecology \& Evolution 21, 451-457.

Armstrong, R. A. \& McGehee, R. (1980). Competitive exclusion. American Naturalist 115, 151-170.

Bell, G. (2000). Distribution of Abundance in Neutral Communities. American Naturalist 155, 606-617.

Bjørnstad, O. N. \& Grenfell, B. T. (2001). Noisy clockworks: time-series analysis of population fluctuations in animals. Science 293, 638-643.

Chase, J. M. (2005). Towards a really unified theory for metacommunities. Functional Ecolology19, 182-186.

Diez, J. M. \& Pullian, H.R. (2007). Hierarchical analysis of species distributions and abundance across environmental gradients. Ecology 88(12), 3144-3152.

Dornelas, M., Connolly, S. R. \& Hughes, T. P. (2006). Coral reef diversity refutes the neutral theory of biodiversity. Nature 440, 80-82.

Engen, S., Lande, R., Walla, T. \& Devries, P.J. (2002). Analyzing Spatial Structure of Communities Using the Two-Dimensional Poisson Lognormal Species Abundance Model American Naturalist 160, 60-73.

Etienne, R. S. \& Olff, H. (2004). A novel genealogical approach to neutral biodiversity theory Ecology Letters 7 , 170-175.

Gause, G. F. (1934). The struggle for existence. Hafner Publishing Company, New York, USA.

Gelman, A., Carlin, J.B., Stern, H.S. \& Rubin, D.B. (2003). Bayesian Data Analysis (2 ${ }^{\text {nd }}$ ed.). Chapman\& Hall.

George, E. I. \& McCulloch, R. E. (1993). Variable selection via Gibbs sampling. Journal of the American Statistical Association 88, 881-889.

Gewin, V. (2006). Beyond Neutrality Ecology Finds Its Niche. PLoS Biology 4(8), e278. 
Gilks, W. R., Richardson, S. \& Spiegelhalter, D. J., Eds. (1996). Markov Chain Monte Carlo in practice Chapman and Hall, London, UK.

Gravel, D., Canham, C. D., Beaudet, M., Messier, C. Reconciling niche and neutrality: the continuum hypothesis. Ecology Letters 9(4), 399-409.

Houlahan, J. E., Currie, D. J., Cottenie, K., Cumming, J. S., Ernest, S. K. M., Findlay, C. S., Fuhlendorf, S. D., Gaedke, U., Legendre, P., Magnuson J. J., McArdle, B. H., Muldavin, E. H., Noble, D. Russel, R, Stevens, R. D., Willis, T. J., Woiwod, I. P., \& Wondzell, S. M. (2007). Compensatory dynamics are rare in natural ecological communities Proc. Natl. Ac. Sci. 104: 3273-3277.

Hubbell, S.P. (2001). The unified Neutral Theory of Biodiversity and Biogeography. Princeton University Press.

Hutchison, G. E. (1957). Concluding remarks Cold Spring Harbor symposium on quantitative biology 22, 415-425.

Maurer, B. A. \& McGill, B.J. (2004). Neutral and non-neutral macroecology.- Basic \& Appl. Ecol. 5: 413 - 422.

McCarthy, M. (2007). Bayesian Methods in Ecology Cambridge University Press, New York.

McGill, B. J. (2003). A test of the unified neutral theory. Nature 422, 881-885.

Mutshinda, C. M., O'Hara, R. B. \& Woiwod, I. P. (2008). Species abundance dynamics under neutral assumptions: a Bayesian approach to the controversy. Functional Ecology 22(2), 340-347.

Poulin, R. (2004). Parasites and the neutral theory of biodiversity. Ecography 27(1), 119-123.

Spiegelhalter, D., Thomas, A., Best, N. \& Lunn, D. (2003). WinBugs version 1.4 User manual. http:// www.mrc-bsu.cam.ac.uk/bug.

Thomas, A., O'Hara, R.B., Ligges, U. \& Sturtz, S. (2006). Making BUGS Open. $\quad$ R News 6, 12-17.

Turnbull, L.A., Manley, L. \& Rees, M. (2005). Niches, rather than neutrality, structure a grassland pioneer guild. Proceedings of the Royal Society B: Biological Sciences, 272 (1570), 1357-1364.

Williamson, M. \& Gaston, K. J. (2005). The lognormal is not an appropriate null hypothesis for the species- abundance distribution. -J. An. Ecol.74: 409-422.

Zhou, S. \& Zhang, D. (2006). Neutral theory in community ecology. Front. of Biol. in China 30(1), 1-8. 